\title{
Genetic diversity of Cryphonectria parasitica causing chestnut blight in South Tyrol (northern Italy)
}

\author{
Farooq Ahmad · Sanja Baric
}

Accepted: 15 November 2021 / Published online: 1 January 2022

(C) The Author(s) 2021

\begin{abstract}
European chestnut (Castanea sativa) is threatened by the invasive fungus Cryphonectria parasitica, which causes chestnut blight. The virulence of the fungus can be reduced by a group of mycoviruses that can spread among vegetatively compatible strains through hyphal anastomosis. Hypovirulent isolates are used as biocontrol agents, but their efficiency can be diminished by restricted hyphal anastomosis if the variability of vegetative compatibility (vc) types in a population is high. Sexual reproduction could increase the vc type diversity and further complicate biocontrol in a region. Therefore, knowledge of genetic diversity of $C$. parasitica is important to assess the effectiveness of a biological control program. The present study was performed in the Autonomous Province of Bozen-Bolzano (South Tyrol) in northern Italy, where chestnut cultivation provides an additional income to farmers. The genetic characterization of $C$. parasitica isolates from 35 chestnut stands and one forest population in different
\end{abstract}

Dedicated to the memory of Professor Giustino Tonon

Supplementary Information The online version contains supplementary material available at https://doi. org/10.1007/s10658-021-02425-2.

F. Ahmad $\cdot$ S. Baric $(\bowtie)$

Faculty of Science and Technology,

Free University of Bozen-Bolzano,

Universitätsplatz 5, 39100 Bozen-Bolzano, Italy

e-mail:sanja.baric@unibz.it districts of South Tyrol was performed based on the analysis of vegetative incompatibility loci, the mating type locus, and the internal transcribed spacer (ITS) region. In this study, a total of 23 different vc types were found all over South Tyrol with a Shannon diversity index of 1.86. EU-2, EU-1, and EU-13 were the most widespread vc types comprising $51 \%$, $13 \%$, and $9 \%$ of the fungal isolates, respectively. Both mating types were present in the region with a ratio close to 1:1. Three different haplotypes were identified based on ITS sequence analysis, which pointed to two introduction events of the fungus to the region and allowed placing $C$. parasitica from South Tyrol into a larger phylogeographic context.

Keywords Population genetics - Chestnut blight . Mating types · Vegetative compatibility · Internal transcribed spacer region

\section{Introduction}

European or sweet chestnut (Castanea sativa) covers an estimated area of 2.5 million hectares in several European countries, including Italy, Spain, France, Greece, and Portugal (EU Science Hub, 2019). While Mediterranean climate particularly favors its growth, chestnut can also be found in other temperate climate regions of Europe and Asia Minor. In Italy, chestnut plantations cover about 52,000 hectares (Castellotti \& Doria, 2016). In the Autonomous Province of 
Bozen-Bolzano (South Tyrol), chestnut stands occur on an area of approximately 123 hectares that are managed by 262 farms, in addition to the forest trees (ASTAT, 2016). Chestnut stands in this region show a fragmented distribution in mid-mountain locations, with an average of 23 trees per owner, while the overall annual production of chestnuts amounts to around 400 tons (Bender, 2002). In the past, chestnuts played an important role as a staple food, especially in mountainous areas (Bellini, 2005). Nowadays, chestnut trees represent an essential element of the local landscape and forests, and provide additional income to farmers. Finally, chestnut stands provide valuable ecosystem services and enhance recreational and touristic activities in the region.

Chestnut trees are susceptible to different diseases and pests. The most widespread and economically important disease is chestnut blight caused by Cryphonectria parasitica (Murrill) Barr (Rigling \& Prospero, 2018). Cryphonectria parasitica induces bark lesions (so-called cankers), which may cause tree death above the infection point (Rigling \& Prospero, 2018). The ascomycete fungus $C$. parasitica originates from Eastern Asia and was accidentally introduced to North America in the early 1900s and to Europe in the 1930s. In Europe, it was first detected in 1938 near the city of Genova, Italy (Biraghi, 1950), and arrived in South Tyrol in 1958, where it subsequently spread to all chestnut growing areas (Windegger, 1994). In the 1950s, a decline in the European chestnut blight epidemic was observed, which was due the appearance of hypovirulence (Biraghi, 1953). However, in recent years, chestnut trees in Europe and South Tyrol have been displaying various degrees of crown dieback, sometimes resulting in complete death of the trees (Waldboth \& Oberhuber, 2009). One reason for this increased mortality of chestnut trees could be a synergistic effect of infection with C. parasitica and climatic stress, i.e., high temperatures in summer and spring, and low precipitation in winter (Waldboth \& Oberhuber, 2009). Climatic stress is positively associated with an increase of fungal infections of trees (Desprez-Loustau et al., 2006); especially water stress seems to promote blight development in C. sativa (Gao \& Shain, 1995). Another reason could be the establishment of the chestnut gall wasp (Dryocosmus kuriphilus) in South Tyrol (Mair, 2009). As a recent study showed, abandoned galls of these insects could serve as entry points for $C$. parasitica (Meyer et al., 2015).

Vegetative compatibility (vc) is the ability of fungal mycelia to fuse with other mycelia of the same species through hyphal anastomosis and to exchange cellular materials (Anagnostakis, 1977). It can be determined either phenotypically by co-culturing the fungi on nutrient media or genotypically by determining the alleles at vegetative incompatibility loci (vic) (Short et al., 2015). Vc was also found to represent an important mechanism to transfer mycoviruses from hypovirulent to virulent strains. Some of the mycoviruses of $C$. parasitica (i.e. Cryphonectria hypovirus 1 [CHV1]) are known to reduce the pathogenicity of the fungus, so they act as biocontrol agents (Milgroom \& Cortesi, 2004). The use of mycoviruses as biocontrol agents led to extensive studies of the occurrence of vc types of $C$. parasitica in several countries, as high vc type diversity may hinder the successful implementation of biocontrol strategies in a region (Bryner \& Rigling, 2012; Cortesi et al., 1996; Mlinarec et al., 2018; Myteberi et al., 2013; Robin et al., 2009; Short et al., 2015; Trestic et al., 2001; Zamora et al., 2012). In Italy, for example, the diversity of vc types of $C$. parasitica was shown to be higher in northern populations than in southern populations (Cortesi et al., 1998; Pennisi et al., 2005). The analysis of vc types can help to identify new genetic variants of the fungus in a particular area, while an increasing number of vc types is considered a good indicator of genetic diversity within a population (Glass \& Kuldau, 1992). Studying vc type diversity also has practical applications because of its connection with hypovirulence and biocontrol potential (Glass \& Kuldau, 1992).

Sexual compatibility in ascomycetes is controlled by a single di-allelic (MAT-1, MAT-2) mating type locus (Coppin et al., 1997). In heterothallic species, sexual reproduction is only possible between mycelia of the opposite mating type (Kronstad \& Staben, 1997). The presence of both mating types in a population indicates the potential for sexual reproduction (Milgroom et al., 2008). A population with allele frequencies close to $1: 1$ has a high potential of sexual reproduction, which contributes to increased genetic diversity, including vc type diversity (Mangil \& Erincik, 2018; Milgroom \& Cortesi, 2004). Consequently, data about the distribution and diversity of mating types in a region is essential to apply biological 
control sustainably (Cortesi et al., 1998; Heiniger \& Rigling, 1994).

In South Tyrol, a high chestnut tree mortality due to infection with $C$. parasitica was observed in the 1980s, which led to the artificial inoculation of more than 6,000 chestnut trees, distributed all over the territory, with four hypovirulent isolates of the fungus (Maresi et al., 1993). The inoculation campaign was preceded by a study in which the vegetative compatibility of $C$. parasitica isolates from different localities was tested against ten vc tester strains. In this investigation, seven different vc types were determined (Maresi et al., 1993). Over the course of 25 years, no follow-up study was performed to assess the development of $C$. parasitica populations in this region. Such investigations would help to assess the effectiveness of a biological control program based on hypovirulence and the potential for disease development (Montenegro et al., 2008). Therefore, the present study aimed to determine the genetic diversity of $C$. parasitica and its potential for sexual reproduction in South Tyrol by analyzing six vic loci and the mating type locus. Furthermore, DNA sequence analysis of the internal transcribed spacer (ITS) region was performed to place $C$. parasitica from South Tyrol into a larger phylogeographic context.

\section{Materials and methods}

\section{Sampling and isolation of $C$. parasitica}

Bark samples of $C$. parasitica cankers from 394 chestnut trees showing characteristic symptoms of chestnut blight were collected in the Autonomous Province of Bozen-Bolzano in spring 2017 and in winters of $2017 / 2018$ and 2018/2019. The diseased portions of branches were initially removed through hand pruning and/or with chain saws by professional tree care specialists. Small branches with disease symptoms were collected from these removed tree parts. When the size of a branch was large, bark portions were cut by a chisel at the border between healthy and necrotic tissue. Up to three cankered branches and/ or bark portions per tree were taken, whenever possible. Thirty-five chestnut stands located in five chestnut growing districts of South Tyrol and one forest population were sampled (Fig. 1). Due to the patchy distribution of chestnut stands with small numbers of trees and the fact that not all trees were infected, extensive sampling of trees with chestnut blight per site was not possible. South Tyrol is a bilingual territory with German and Italian as official languages, also applying to geographic names. Nevertheless, for the sake of clarity, only the Italian names are used in the text, while the names in both languages are provided in the figures and tables. The collected symptomatic plant material was incubated in moist chambers at room temperature for 7-20 days. Pycnidia grown on the bark of the samples were removed with a sharp razor and inoculated on Potato Dextrose Agar (PDA) medium manufactured by VWR (Leuven, Belgium) at room temperature in the dark. A total of 274 pure cultures were obtained from the collected samples. Cultures were transferred to slant PDA at room temperature for one week and maintained at $4{ }^{\circ} \mathrm{C}$.

DNA isolation and molecular genetic analysis

DNA was extracted following the procedure described by Cassago et al. (2002) with some minor changes such as centrifugation at $4{ }^{\circ} \mathrm{C}$ after adding isopropanol to increase the efficiency of DNA precipitation. After washing with $70 \%$ ethanol, the DNA pellet was left to dry at room temperature overnight. DNA was suspended in TE-buffer (pH 8), kept at $4{ }^{\circ} \mathrm{C}$ for shortterm storage, and finally stored at $-20{ }^{\circ} \mathrm{C}$.

Characterization of $C$. parasitica isolates based on vegetative compatibility alleles was done using a PCR protocol developed by Short et al. (2015) and adapted by Mlinarec et al. (2018), with minor changes of reagents and PCR conditions as explained below. The amplification of the MAT locus was done following a PCR protocol developed by Marra and Milgroom (1999) and McGuire et al. (2001). The PCR reaction was prepared with $10 \mu \mathrm{l}$ of 2X PCRBIO HS Taq Mix (PCR Biosystems, London, United Kingdom), $1 \mu$ l of DNA extract, the appropriate concentration of each primer (Supplementary Table 1), and nuclease-free water to adjust the final volume to $20 \mu \mathrm{l}$. The PCR conditions were the following: $95{ }^{\circ} \mathrm{C}$ for $2 \mathrm{~min}$ followed by 40 cycles of $95{ }^{\circ} \mathrm{C}$ for $30 \mathrm{~s}$, the locus-specific annealing temperature for $30 \mathrm{~s}$ (vic), or $45 \mathrm{~s}$ (MAT) (see Supplementary Table 1), and $72{ }^{\circ} \mathrm{C}$ for $1 \mathrm{~min}$ and $45 \mathrm{~s}$. The final extension was performed at $72{ }^{\circ} \mathrm{C}$ for 10 min. Amplified allele products were visualized on $1.5 \%$ agarose gels after $60 \mathrm{~min}$ of electrophoretic 


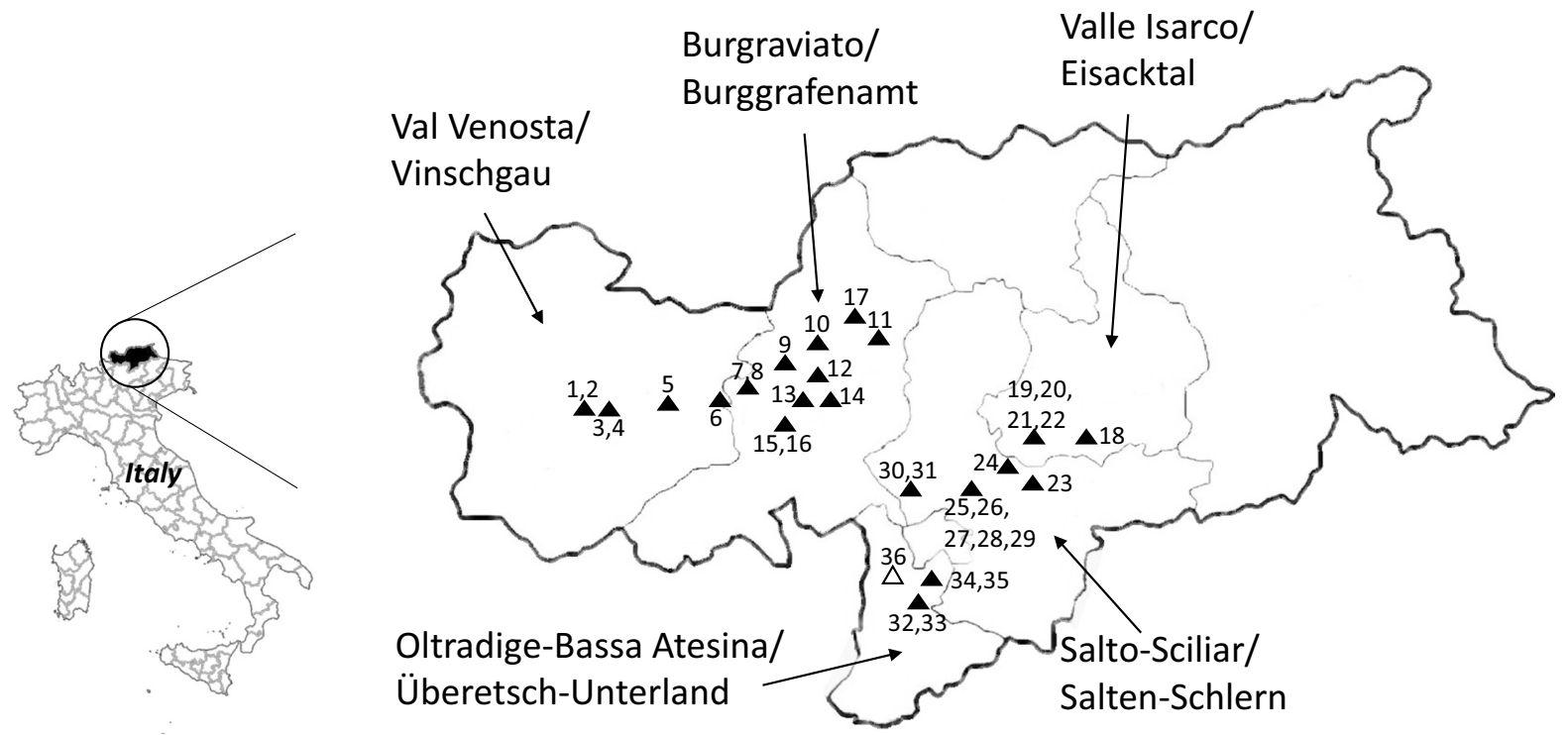

Fig. 1 Map of Italy on the left with the borders of provinces indicated in grey, while the area of the Autonomous Province of Bozen-Bolzano (South Tyrol) is highlighted in black. Enlarged representation of the territory of South Tyrol on the right indicating the districts where chestnut is grown and where sampling was performed. Black triangles show the locations of the chestnut stands that were sampled, while the white triangle in Oltradige-Bassa Atesina shows the location of the Monticolo forest. Each sampling site is represented by a number on the map: Vinschgau/Val Venosta: 1, TAP (Kortsch/ Corces); 2, WIN (Kortsch/Corces); 3, GOG (Schlanders/ Silandro); 4, VET (Schlanders/Silandro); 5, KGK (Kastelbell/ Ciardes); 6, AUF (Naturns/Naturno); 7, ALTO (Töll/Tel); 8, WEIR (Töll/Tel); Burggrafenamt/Burgraviato: 9, ALAL (Alt Algund/Lagundo); 10, BRUG (Dorf Tirol/Tirolo); 11, MOAR (Schenna/Scena); 12, CRIS (Meran/Merano); 13, WIB (Burg-

separation at $80 \mathrm{~V}$. Isolates were assigned to EU types (vc types) according to the vic allelic data defined by Cortesi and Milgroom (1998).

ITS amplification was performed for 41 isolates from different sampling localities. PCR reactions consisted of $7.5 \mu \mathrm{l}$ of $2 \mathrm{X}$ PCRBIO HS Taq Mix, $0.3 \mu \mathrm{M}$ of each primer (Lévesque \& De Cock, 2004; Supplementary Table 1), $1 \mu \mathrm{l}$ of DNA extract, and nuclease-free water to adjust the final reaction volume to $15 \mu \mathrm{l}$. PCR conditions used for the amplification of ITS were as follows: $95{ }^{\circ} \mathrm{C}$ for $2 \mathrm{~min}$ followed by 35 cycles of $95{ }^{\circ} \mathrm{C}$ for $30 \mathrm{~s}, 60{ }^{\circ} \mathrm{C}$ for $45 \mathrm{~s}$, and $72{ }^{\circ} \mathrm{C}$ for $1 \mathrm{~min}$. The final extension was accomplished at $72{ }^{\circ} \mathrm{C}$ for $5 \mathrm{~min}$.

After separating and visualizing the PCR products of the ITS region on agarose gels, the amplicons were
stall/Postal); 14, KAL (Lana); 15, BLAS (Völlan/Foiana); 16, OBER (Völlan/Foiana); 17, BRUN (Saltaus/Saltusio); Eisacktal/Valle Isarco:18, ISC (Lajen/Laion); 19, OBG (Barbian/ Barbiano); 20, OBK (Barbian/Barbiano); 21, SPR (Barbian/ Barbiano); 22, TSB (Barbian/Barbiano); Salten-Schlern/SaltoSciliar: 23, FLK (St. Oswald - Seis/Sant'Osvaldo - Siusi); 24, GRU (Rotwand - Ritten/Pietrarossa - Renon); 25, NOP (Lengstein - Ritten/Longostano - Renon); 26, PIE (Lengstein - Ritten/Longostano - Renon); 27, JOG (Siffian - Ritten/Siffiano Renon); 28, TES (Unterinn - Ritten/Auna di Sotto - Renon); 29, KLS (Signat - Ritten/Signato - Renon); 30, NOC (Sill - Ritten/Sill - Renon); 31, PLA (Sill - Ritten/Sill - Renon); Überetsch-Unterland/Oltradige-Bassa Atesina: 32, HOAN (Leifers/Laives); 33, UNT (Leifers/Laives); 34, MUL (Steinmannwald/Pineta); 35, RUTT (Steinmannwald/Pineta); 36, MON (Montiggler Wald/Bosco di Monticolo)

purified using the enzymatic PCR cleanup A'SAP (ArcticZymes, Troms $\emptyset$, Norway) following the standard protocol of the manufacturer. Sanger sequencing of the ITS region was done by the company Microsynth Seqlab GmbH (Göttingen, Germany) using the forward and reverse amplification primers. It was not always possible to obtain a complete sequence of the ITS region with the external primers due to the presence of repetitive $\operatorname{poly}(\mathrm{C})$ and poly( $\mathrm{T})$ stretches approximately $150 \mathrm{bp}$ and $100 \mathrm{bp}$ from the forward and reverse primer binding sites, respectively, which led to premature termination of the sequencing reaction. To sequence the entire ITS region, two internal primers (ITS-INT-F and ITS-INTR2) were designed by using the software Geneious Prime, version 2019.0.4 (Biomatters Ltd., Auckland, 
New Zealand). These internal primers were used as sequencing primers for those samples, for which the external primers did not provide complete sequence information (Supplementary Fig. 1; Supplementary Table 1).

\section{Co-culturing assay}

Few $C$. parasitica isolates could not be assigned to a particular vc type by molecular analysis because allelic information at one or two vic loci was missing and as repeated PCRs did not result in any product. Such isolates were subjected to co-culturing with possible vc types to assign them to a particular vc type. This co-culturing with two or four possible ve types was done by using the method described by Anagnostakis (1977).

\section{Data analysis}

To compare the data obtained in the present study with other findings, the mean number of vc types determined in populations of different countries was calculated by dividing the sum of vc types found in all populations by the count of populations in each country. To determine the diversity of vc types for each geographic area or district, the Shannon diversity index $\left(\mathrm{H}^{\prime}\right)$ was calculated according to the formula: $\mathrm{H}$ ' $=-\sum\left(\mathrm{p}_{i} \times \ln \left(\mathrm{p}_{i}\right)\right)$, where ' $\mathrm{P}_{\mathrm{i}}$ " is the frequency of $i$ th vc type (Tramer, 1969). The evenness index (E) is a way to measure the distribution of genotypes within a region (Pielou, 1966). For a given number of vc types, the evenness index is maximum when the individuals are distributed among the genotypes as evenly as possible. If only a few of the genotypes contain a large majority of the individuals, the index is low. It was calculated with the formula: $\mathrm{E}=\mathrm{H}^{\prime} / \ln (\mathrm{S})$ (Pielou, 1966), where "S" refers to the total count of vc types found in a region (Tuomisto, 2010). Allele diversity for each locus was calculated according to Nei (1973) with the software POPGENE version 1.32 and the mean diversity $(\hat{H})$ of each district was calculated as the average of allele diversities across all six loci. The software POPGENE version 1.32 (Yeh et al., 1999) was used to obtain an UPGMA dendrogram based on Nei's genetic distances in order to represent the relationships among $C$. parasitica subpopulations from different chestnut stands in South Tyrol considering the frequencies of vc types. Mating type ratios were tested in all districts for deviation from 1:1 using chi-squared statistics in Microsoft Excel 2016. A t-test as implemented in the software SigmaPlot version 14.5 was performed in order to check whether chestnut stands with both mating types displayed a higher number of vc types than those with a single mating type. The same software was employed for the construction of some of the graphical representation of data.

All electropherograms of DNA sequences of the ITS region obtained with different primers were visually inspected for their quality using the software Geneious Prime. For each isolate, an alignment comprising the sequences obtained with different primers was obtained using the de-novo assemble function in Geneious Prime. The consensus sequence of each isolate was exported as a separate FASTA file. To construct a global haplotype network, 142 ITS sequences of $C$. parasitica present in GenBank (NCBI) from different regions of the world were downloaded and aligned with the 41 DNA sequences obtained in the present study using the MUSCLE alignment online tool (https://www. ebi.ac.uk/Tools/msa/muscle). Alignments were checked visually for any ambiguities and manually edited if necessary. Since insertion-deletion mutations (indels) are not considered variable sites by the algorithm selected to construct the haplotype network but are regarded informative for phylogenetic studies (Nagy et al., 2012), indels were coded as substitutions to increase the resolution of the haplotype network. Sequence analysis was done using DnaSP (version 6) to calculate the amount of monomorphic and polymorphic sites. The FASTA file obtained from MUSCLE was changed to NEXUS format using the software Mesquite (version 3.6). The NEXUS file was imported to the software PopART, version 1.7 (Leigh \& Bryant, 2015) along with the information about the country or region of origin of each sequence to construct a haplotype network. The haplotype network was constructed using the Median-joining network algorithm (Bandelt et al., 1999), with the parameter epsilon set to zero in PopART (Leigh \& Bryant, 2015). Nucleotide diversity was also calculated using the default settings of PopART. 


\section{Results}

The multilocus PCR assay produced clear and distinguishable specific amplicons of expected sizes for all vic loci. Among 274 isolates, 261 were successfully genotyped for the complete set of vic loci, whereas 13 had missing allelic information at one or two loci due to non-amplification. However, the 13 isolates with missing allelic information were assigned to vc types through a co-culturing assay and were considered in the data analysis. The investigated isolates of C. parasitica from South Tyrol displayed allelic polymorphism at five vic loci (vic1a, vic2, vic4, vic6, vic7), whereas one locus (vic3a) was monomorphic in all the isolates and only allele vic3a-1 was found. Allelic frequencies of each locus are shown in Table 1. Twenty-three different vc types of $C$. parasitica were found in South Tyrol (Fig. 2) with a mean of 9.17 per district (Supplementary Fig. 2). EU-2 was the most frequent $\mathrm{vc}$ type in the region with a frequency of $51.1 \%$ among all the isolates. EU-1 (12.8\%) and EU-13 (8.8\%) were the second and third most common vc types found in South Tyrol, respectively, followed by EU-5 and EU-17, both with a frequency of $5.8 \%$ (Fig. 2; Table 2). A total of $84.3 \%$ of the isolates analyzed were assigned to one of the five most common vc types. EU-2 was dominant in the major part of districts, Val Venosta (67.2\%), Burgraviato (63.9\%), Valle Isarco (75.7\%), and Salto-Sciliar (36.4\%). In the Monticolo forest population, EU-1 was dominant (50\%), whereas in Oltradige-Bassa Atesina, three vc types, EU-1 (25\%), EU-2 (25\%), and EU-13 (25\%) were found at the same frequency. Among 35 chestnut stands, 30 carried $C$. parasitica with more than one vc type (ranging from 2 to $7 \mathrm{vc}$ types), while $C$. parasitica from five chestnut stands had a single vc

Table 1 Allelic frequencies of different vic loci present in the isolates of Cryphonectria parasitica in South Tyrol

\begin{tabular}{lll}
\hline Locus & $\begin{array}{l}\text { Frequency } \\
\text { of allele } 1\end{array}$ & $\begin{array}{l}\text { Frequency of } \\
\text { allele 2 }\end{array}$ \\
\hline vic1a & 0.17 & 0.83 \\
vic2 & 0.66 & 0.34 \\
vic3a & 1.00 & 0.00 \\
vic4 & 0.22 & 0.78 \\
vic6 & 0.21 & 0.79 \\
vic7 & 0.22 & 0.78 \\
\hline
\end{tabular}

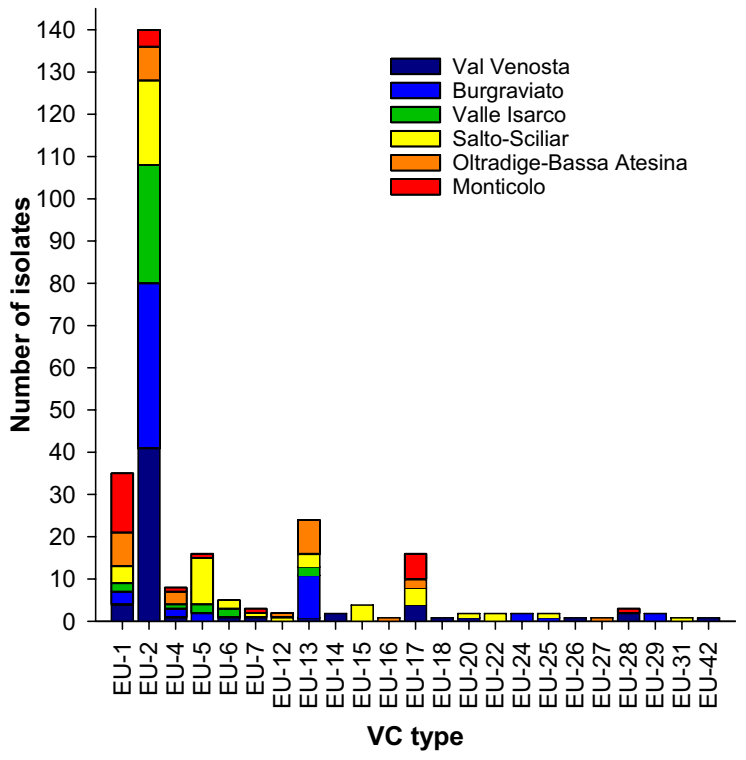

Fig. 2 Different vc types of Cryphonectria parasitica and their total numbers found in the chestnut growing districts of South Tyrol

type. On average, each chestnut stand had $2.9 \pm 1.4$ (standard deviation, SD) different vc types (excluding chestnut stands BLAS, OBER, and TES, from which only one or two isolates of $C$. parasitica could be obtained), whereas the forest population of Monticolo had seven different vc types of $C$. parasitica.

In the Salto-Sciliar district, the highest vc type diversity of $C$. parasitica in terms of number of vc types and the Shannon diversity index was found. Valle Isarco, in contrast, showed the lowest degree of diversity, both based on the number of different vc types and the Shannon diversity index (see Table 2). Oltradige-Bassa Atesina had the highest evenness index, whereas it was lowest in Val Venosta. The mean allele diversity was also the highest in Oltradige-Bassa Atesina and the lowest in Valle Isarco. The mean values of the number of vc types found per district in South Tyrol were higher when compared with other European populations except those of Bosnia-Herzegovina and Switzerland (Supplementary Fig. 2).

Out of 274 isolates, 249 were successfully genotyped and assigned to mating type idiomorphs (either MAT-1 or MAT-2). For 25 isolates, it was not possible to obtain any result as 10 isolates amplified for both mating types and showed double bands whereas 
Table 2 Vc types of Cryphonectria parasitica present in different districts of South Tyrol along with the diversity and evenness index of ve types

\begin{tabular}{|c|c|c|c|c|c|c|c|}
\hline Sampling district & $\mathrm{N}$ isolates & $\mathrm{N}$ vc types & $\begin{array}{l}\text { Sample size } \\
\text { ratio }^{\text {a }}\end{array}$ & $\begin{array}{l}\text { Top } 3 \text { vc types } \\
\text { (frequency) }\end{array}$ & $\begin{array}{l}\text { Shannon diver- } \\
\text { sity index (H') }\end{array}$ & $\begin{array}{l}\text { Evenness } \\
\text { index }(\mathrm{E})\end{array}$ & $\hat{\mathrm{H}}^{\mathrm{b}}$ \\
\hline Vinschgau/Val Venosta & 61 & 13 & 4.7 & $\begin{array}{l}\text { EU-2 (0.67), EU-1 (0.07), } \\
\text { EU-17 (0.07) }\end{array}$ & 1.39 & 0.54 & 0.19 \\
\hline Burggrafenamt/Burgraviato & 61 & 8 & 7.6 & $\begin{array}{l}\text { EU-2 (0.64), EU-13 } \\
(0.16), \text { EU-1 (0.05) }\end{array}$ & 1.25 & 0.60 & 0.30 \\
\hline Eisacktal/Valle Isarco & 37 & 6 & 6.2 & $\begin{array}{l}\text { EU-2 (0.76), EU-1 (0.05), } \\
\text { EU-5 (0.05), EU-6 } \\
(0.05), \text { EU-13 (0.05) }\end{array}$ & 0.94 & 0.52 & 0.15 \\
\hline Salten-Schlern/Salto-Sciliar & 55 & 13 & 4.2 & $\begin{array}{l}\text { EU-2 (0.36), EU-5 (0.20), } \\
\text { EU-1 (0.07) }\end{array}$ & 2.03 & 0.79 & 0.33 \\
\hline $\begin{array}{l}\text { Überetsch-Unterland/Oltra- } \\
\text { dige-Bassa Atesina }\end{array}$ & 32 & 8 & 4.0 & $\begin{array}{l}\text { EU-1 (0.25), EU-2 (0.25), } \\
\text { EU-13 (0.25) }\end{array}$ & 1.76 & 0.85 & 0.39 \\
\hline $\begin{array}{l}\text { Montiggler Wald/Bosco } \\
\text { di Monticolo (Monticolo } \\
\text { forest) }\end{array}$ & 28 & 7 & 4.0 & $\begin{array}{l}\text { EU-1 (0.50), EU-17 } \\
\quad(0.21), \text { EU-2 (0.14) }\end{array}$ & 1.43 & 0.74 & 0.23 \\
\hline Total (South Tyrol) & 274 & 23 & 11.9 & $\begin{array}{l}\text { EU-2 (0.51), EU-1 (0.13), } \\
\text { EU-13 (0.09) }\end{array}$ & 1.86 & 0.59 & 0.29 \\
\hline
\end{tabular}

${ }^{a}$ Ratio of the number of isolates obtained and the number of vc types identified

${ }^{\text {b }}$ Allele diversity for each locus was calculated according to Nei (1973). Mean diversity $(\hat{\mathrm{H}})$ is the average of allele diversities over all six loci

15 isolates showed no band on the agarose gel. Out of 249 isolates, $126(50.6 \%)$ were identified as MAT1, whereas 123 (49.4\%) were MAT-2. In South Tyrol, mating type ratios were not significantly different from 1:1 $\left(\mathrm{X}^{2}=0.004\right.$; $\mathrm{P}$ value from the $\mathrm{X}^{2}$ test for deviation from 1:1 ratio $>0.05)$. Within South Tyrol, 21 out of 35 chestnut stands had $C$. parasitica with both mating types. Fourteen stands from all districts, except Salto-Sciliar, had $C$. parasitica with a single mating type (either MAT-1 or MAT-2). In Val Venosta and Valle Isarco, MAT-1 was the dominant (78.8\% and $67.6 \%$, respectively) mating type, whereas in Burgraviato the dominant mating type was MAT-2 (80.0\%). Oltradige-Bassa Atesina, Salto-Sciliar, and Monticolo forest had $C$. parasitica with both mating types in a more or less equal frequency (Fig. 3).

In South Tyrol, $C$. parasitica isolates of five vc types were found to be associated with a particular mating type (significant deviation from 1:1) i.e., EU-2 isolates had dominant MAT-1 whereas EU-4, EU-5, EU-13 and EU-15 isolates had dominant MAT-2 (Supplementary Fig. 3). Isolates of the remaining vc types had mating type ratios that did not significantly deviate from 1:1. Rare vc types, such as EU-7, EU-14, EU-15, EU-16, EU-18, EU-20, EU-22,
EU-24, EU-25, EU-26, EU-27, EU-28, EU-31 and EU-42, were found to have a single mating type. Six vc types were isolated only once, so it was obvious that they had a single mating type. On average, chestnut stands with one mating type had $1.9 \pm 0.7$ (SD) vc types, while those with both mating types had $3.3 \pm 1.2$ (SD). The t-test showed that the difference in the mean values of the two groups were greater than would be expected by chance $(\mathrm{P}<0.001)$. The chestnut stands BLAS, OBER and TES were not considered in this statistic as was the forest population Monticolo, in order to compare groups with similar sample sizes.

The PCR products of the ITS region of $C$. parasitica showed a clear band of approximately $650 \mathrm{bp}$ on the agarose gel. Ten isolates were sequenced with external primers only, whereas 31 isolates were sequenced using four primers (two external and two internal primers) because external primers alone did not allow to sequence the ITS region completely. After alignment and trimming at either end, sequences with a length from 557 to $561 \mathrm{bp}$ were obtained. Among 41 isolates sequenced, three different haplotypes (referred to as $\mathrm{H} 1, \mathrm{H} 2$ and $\mathrm{H} 3$ ) were found in South Tyrol (Fig. 4). H2 was the most 


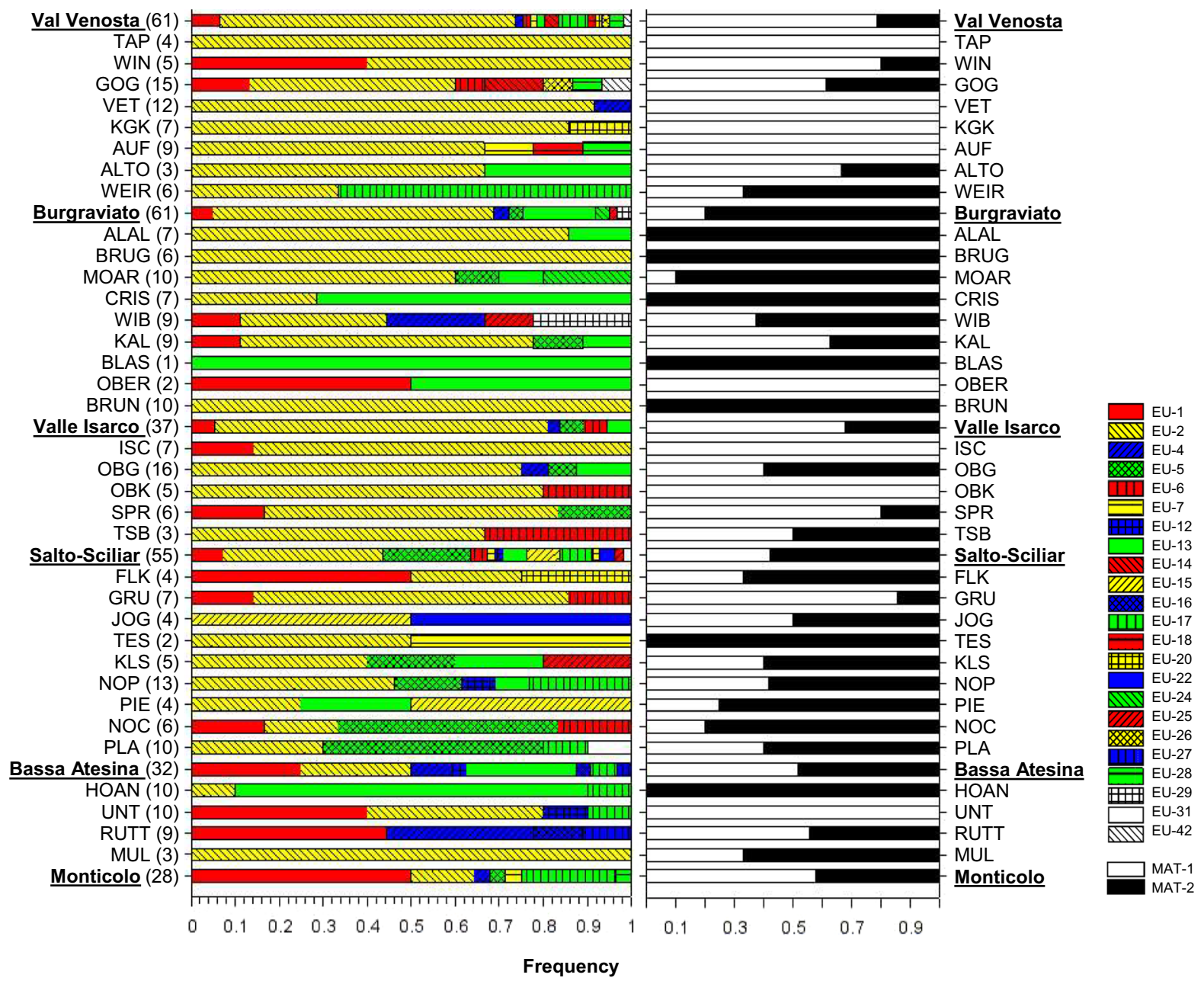

Fig. 3 Frequencies of vc types (left) and mating type (right) of Cryphonectria parasitica found in different sampling areas (districts) of South Tyrol (bold) as well as in each chestnut stand. The three- or four-letter codes of chestnut stands can

common haplotype in South Tyrol, followed by H1. Haplotypes $\mathrm{H} 1$ and $\mathrm{H} 2$ were found in all districts except Valle Isarco and the Monticolo forest, respectively (Fig. 4b). The least common haplotype H3 was only found in Burgraviato, Salto-Sciliar and Monticolo forest. Sequence comparison based on an alignment of 563 bp showed nine variable sites, eight of which were indels. One substitution (transition) was found at position 503 of the alignment of the three haplotypes, where $\mathrm{H} 1$ showed a cytosine, while $\mathrm{H} 2$ and $\mathrm{H} 3$ showed a thymine. The sequences of the three haplotypes were deposited in GenBank under be looked up in legend of Fig. 1. The numbers in parentheses following the codes on the left indicate the number of isolates obtained from different cankers

the accession numbers MW759487, MW759488 and MW759489.

One hundred and forty-two sequences of the ITS region downloaded from GenBank were aligned with sequences of 41 isolates from South Tyrol that made a total of 183 sequences. After trimming, the alignment had a length of 519 bp with 96 polymorphic sites, comprising 82 substitutions and 14 positions with indels. Forty-one different haplotypes were found based on ITS sequences of $C$. parasitica originating from different regions of the world using the sequence analysis feature of DnaSP. The medianjoining network pointed to a geographical clustering 
of some haplotypes from America, Asia or Europe (Fig. 4a). Haplotype H1 was not only found in South Tyrol but is the most common genotype of $C$. parasitica globally. In contrast, haplotypes $\mathrm{H} 2$ and $\mathrm{H} 3$ were found to be unique to this region. The latter haplotypes only differed in a single indel and showed the highest similarity to a haplotype from Asia. While $C$. parasitica isolates with haplotype $\mathrm{H} 1$ were linked to seven different vc types, those with haplotypes $\mathrm{H} 2$ and $\mathrm{H} 3$ were associated with two or three different vc types, respectively (Fig. 4c).

\section{Discussion}

Following apple and grapevine, chestnut represents the third frequent permanent culture in South Tyrol, which usually grows on steeper slopes at the edge of the Adige and Isarco river valleys at elevations between 400 and $700 \mathrm{~m}$ above sea level. Although the direct economic role of chestnut cultivation in South Tyrol is rather minor, it can represent an important additional income (Bossi Fedrigotti \& Fischer, 2015). In South Tyrol, chestnut blight was first noticed in 1958 and since the 1990s, a disease control program has been implemented by official authorities. Genetic diversity of $C$. parasitica was investigated in different European regions, but so far, no such study was performed in South Tyrol, even though it could considerably support the implementation of disease management strategies. The analysis of the vic loci, the mating type locus, and sequences of the ITS region performed in the present study point to a considerable degree of genetic variability of the pathogen in this region. In a study conducted in the 1990s, seven different vc types were identified by applying a traditional co-culturing assay (Maresi et al., 1993). In comparison, 23 different vc types could be identified in the present investigation based on genotypic information at six vic loci. Thus, the number of different vc types seems to have at least triplicated in the past 25 years. Nevertheless, a direct comparison of the data needs to be taken with caution, as: (1) different laboratory techniques were employed, which could have an impact on the resolution, and (2) the present study included a considerably higher number of samples as compared to the previous one (Maresi et al., 1993). An increase in the number of vc types over time was observed in different European countries. For instance, in Croatia, 18 different vc types were found in the 2000s (Krstin et al., 2008), which increased to 26 in 2015 (Mlinarec et al., 2018). In Western Spain, six vc types were found in 2008 (Montenegro et al., 2008), whereas eleven were identified in 2012 (Zamora et al., 2012). In Southwestern Germany, five vc types were detected in 2010 (Peters et al., 2012), but the number increased to 13 in 2014 (Peters et al., 2014). The increase in vc type and genetic diversity of $C$. parasitica populations can be driven by different factors that will be discussed in the following sections.

Vc type diversity of $C$. parasitica in a geographic area may increase for different reasons. For example, fungal spores can be transported over longer distances by birds, insects, and wind. Anagnostakis (1987) reported that in Italy, virulent strains of C. parasitica could travel at an approximate rate of $30 \mathrm{~km} /$ year. Consequently, it is possible that new vc types arrived in South Tyrol from more diverse neighboring populations, such as those in northern Italy (Robin \& Heiniger, 2001). Prospero and Rigling (2012) found that the migration of $C$. parasitica from divergent genetic pools might have increased the genetic diversity (including ve type diversity) in Switzerland. In addition to natural processes, human-mediated activities, such as the import of planting material from other countries or regions, might have contributed to the increase of vc type diversity in South Tyrol (Pérez-Sierra et al. 2019).

Sexual reproduction in $C$. parasitica may further increase vc type diversity (Mangil \& Erincik, 2018; Milgroom \& Cortesi, 2004). Our study reveals the presence of both mating types in all geographic areas of South Tyrol that would point to a high potential for sexual reproduction in the region. Indeed, sexual recombination between the most dominant vc types found in the region, i.e., EU-1 (2212-22) with EU-13 (1211-11) and EU-2 (2112-22) with EU-13 (1211-11), can theoretically produce 16 and 32 different vc types, respectively (Cortesi \& Milgroom, 1998). All vc types found in South Tyrol could have formed by the recombination between EU-2 and EU-13, whereas nine vc types could have originated from the cross between EU-1 and EU-13. In some districts, such as Oltradige-Bassa Atesina and Salto-Sciliar as well as in the Monticolo forest, the distribution of mating type idiomorphs was not significantly different from the 1:1 ratio. Populations of 
a

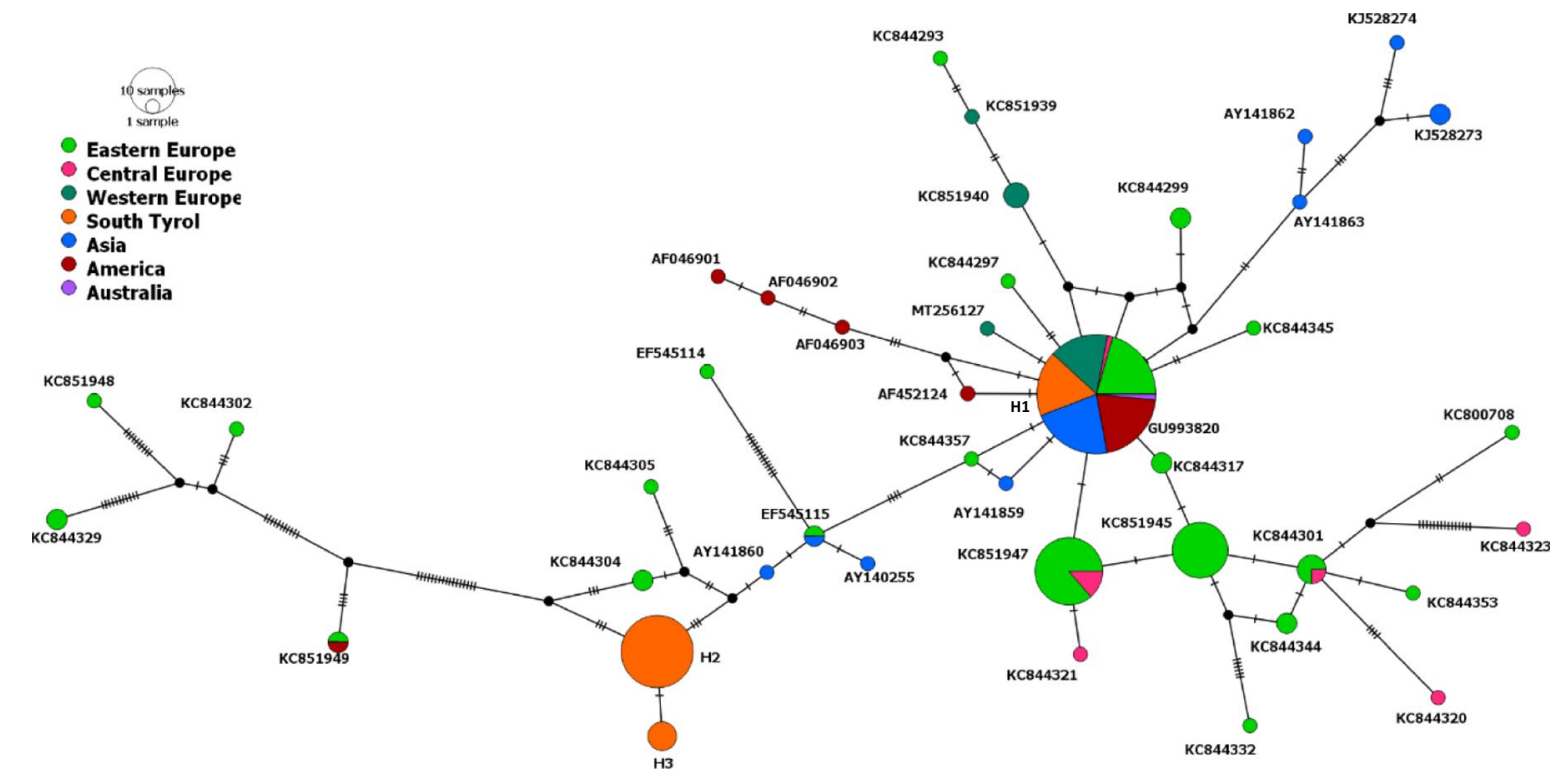

b

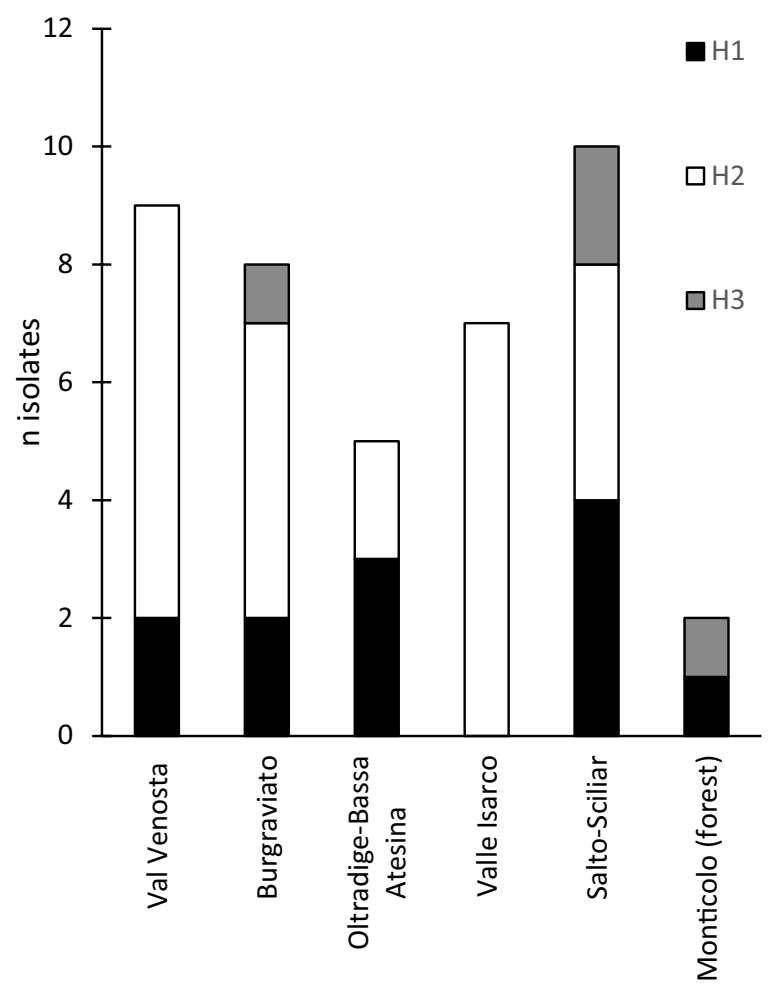

C

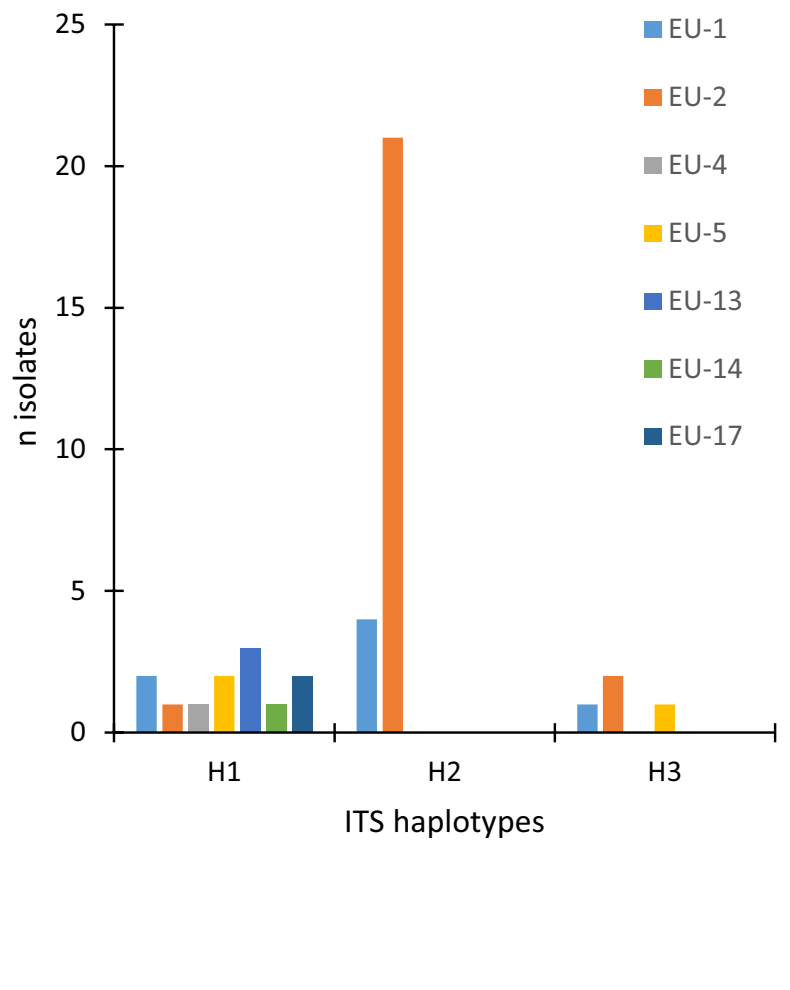

C. parasitica in these districts should theoretically have a higher rate of sexual reproduction and, hence, a higher vc type diversity than populations in which one mating type is dominant. This hypothesis is well supported in Salto-Sciliar, which had the highest vc type diversity and Shannon diversity index, but not in 
4Fig. 4 Median-joining network of ITS haplotypes of Cryphonectria parasitica constructed using PopART (Leigh \& Bryant, 2015). In addition to the ITS sequences obtained from isolates collected in South Tyrol, sequences of this species from other countries and continents that could be found in GenBank were included in the analysis. The haplotypes are represented by circles and their size reflects the haplotype frequency in the dataset of 183 isolates. Different colors represent the geographic origin of the haplotypes. The labels $\mathrm{H} 1, \mathrm{H} 2$ and $\mathrm{H} 3$ denote the three haplotypes found in South Tyrol, while the other haplotypes are represented by a GenBank accession number. Each cross-section line indicates a mutational step. Black small dots represent the theoretical median vectors determined by the software (a). Occurrence of the three ITS haplotypes $\mathrm{H} 1, \mathrm{H} 2$ and $\mathrm{H} 3$ in different districts of South Tyrol (b) and the association of ITS haplotypes of $C$. parasitica with ve types in South Tyrol. Each color represents a different vc type (c)

Oltradige-Bassa Atesina and Monticolo forest. A possible explanation for this finding could be the lower number of samples obtained from Oltradige-Bassa Atesina and Monticolo forest than from other districts. However, the presence of both mating types in a region does not automatically result in sexual reproduction. In Turkish and Macedonian populations, for example, both mating types were present, but no sexual structures (perithecia) were found (Daldal et al., 2018; Sotirovski et al., 2004). To sexually reproduce, it is important for both mating type strains to be physically close to each other. Considering the patchy distribution of chestnut stands in South Tyrol, it appears more likely that sexual reproduction would take place within chestnut stands but less likely among them. In fact, the patterns of distribution and frequency of vc types in different chestnut stands display a high degree of variability and a lack of geographic clustering (see also Supplementary Fig. 4). This is particularly evident in the district of Oltradige-Bassa Atesina, where samples were taken from four chestnut stands in a linear distance of maximally $4.5 \mathrm{~km}$. Cryphonectria parasitica populations from these sites, however, differed in the composition of $\mathrm{vc}$ and mating types, pointing to an isolated occurrence of fungal populations on a small geographic scale. Similarly, in southern Italy, the spatial isolation between fungal strains was thought to be responsible for a low rate of recombination (Liu et al., 1996). Therefore, stochastic processes, such as genetic drift, may play a major role in shaping the variability of fungal genotypes at different sites (Milgroom et al., 1996). In our study, chestnut stands with a single mating type generally showed a lower number of vc types than chestnut stands with both mating types, indicating that sexual reproduction may occur in the latter. Hence, the assessment of the presence of perithecia in the field would be helpful to verify the occurrence of sexual reproduction, whereas the analysis of microsatellite loci could give a better estimate about the actual rate of sexual reproduction in a region (Dutech et al., 2010).

Hypovirulent strains belonging to four different vc types, which identity is unknown, were artificially introduced to South Tyrol in the 1990s to control chestnut blight (Maresi et al., 1993) and might have influenced the population structure of the fungus. Although it is not possible to compare the vc type data with the results of Maresi et al. (1993), we speculate that some of these strains may still be present in the region, as some hypovirulent strains were shown to be better able to disseminate and become established in a population (Morozov et al., 2007; Robin et al., 2010). For example, in France subtypes F1 and F2 strongly decreased the growth and sporulation of the fungus and were not able to disperse and establish in a fungal population. In contrast, the lower virulence of subtype I against the fungal host resulted in greater ecological fitness and a higher potential for dissemination and establishment (Robin et al., 2010). Apart from hypovirulence, other reasons influencing the fitness and consequently the pre-dominance of some vc types of $C$. parasitica may exist. Arabi and Jawhar (2007) demonstrated that in the ascomycete Cochliobolus sativus, vc type is correlated with virulence, i.e., the pre-dominant vc types were found to be more virulent than rare vc types. It could be worth determining if the fungal virulence is correlated with vc types in $C$. parasitica. Furthermore, data on the relative virulence of each vc type and the diversity of viruses present in the region associated with $C$. parasitica would enable a more precise evaluation of the potential damage and to adjust the control measures.

The ITS region has been widely used to study the phylogenetic relationships at the interspecific and intraspecific levels in fungi (Gottlieb \& Lichtwardt, 2001; Poczai \& Hyvönen, 2010; Takamatsu et al., 1999). Although the population genetics of C. parasitica was extensively studied based on vic and microsatellite loci, there was only one study based on ITS sequence analysis that was performed in Eastern Europe, where a considerable degree of 
ITS sequence variation was found (Görcsös et al., 2015). In addition, Görcsös et al. (2015) found that the variability of ITS sequences of $C$. parasitica was not related to geographical distribution and suggested that human-mediated introductions (such as infected propagation material) might be responsible for the observed patterns. In South Tyrol, three different ITS haplotypes were identified and their phylogeographic relationship was assessed in a global context. Finding different haplotypes in the study area could be explained by two hypotheses: the ITS sequence diversity of $C$. parasitica evolved locally or the different haplotypes were introduced from other geographic areas. Since $C$. parasitica is a relatively recently introduced pathogen in Europe, it seems highly unlikely that haplotypes differing at nine variable sites are a result of local evolution, especially when considering the mutation rates of ITS (Kasuga et al., 2002). The central European population of $C$. parasitica was established after the fungus was accidentally introduced from North America to the area close to Genoa in northwestern Italy, from where it spread to other European chestnut growing regions (Milgroom et al., 1996, 2008). As ITS haplotype H1 was found to be widespread not only in South Tyrol but also in other European regions and on other continents, including Asia and America (Fig. 4), it is probable that this haplotype was initially introduced to this region. This assumption is further supported by the fact that haplotype $\mathrm{H} 1$ was associated with seven different vc types in South Tyrol. Haplotypes H2 and H3, instead, were unique to South Tyrol and were associated with only two and three vc types, respectively, which indicates that these haplotypes may have arrived later in this region and did not have enough time to evolve into different vc types. Evidence for at least two independent introduction events of $C$. parasitica from North America and Asia was found in France based on the analysis of vic loci and microsatellite loci (Dutech et al., 2010, 2012; Robin et al., 2009). In the case of South Tyrol, it is not possible to determine the origin from which haplotypes $\mathrm{H} 2$ and $\mathrm{H} 3$ could have been introduced. From the median-joining network, they appear to be closer related to haplotypes found up to now in Asia and Eastern Europe. However, these haplotypes may also be present in Central European or Italian populations, for which ITS sequence data are still under-represented in GenBank (NCBI). Nevertheless, in addition to other molecular genetic markers, ITS sequence analysis of $C$. parasitica could contribute to a better understanding of the phylogeography of this pathogen. Therefore, we suggest a more extensive ITS sequence analysis from geographic areas that are so far under-represented, such as Western and Central Europe, America, and Asia.

The present study provides a first insight into the occurrence of different vc types and mating types of C. parasitica in South Tyrol and contributes towards improved disease management of chestnut blight in the region. Although a total of 23 different vc types were found, $73 \%$ of the isolates belonged to three dominant vc types, namely EU-2, EU-1, and EU-13, which were present in most chestnut stands. Consequently, an effective spread of the hypovirus among chestnut blight affected trees is expected to occur. Nevertheless, the patchy distribution of chestnut stands seems to affect the composition of the fungal populations, which should be considered before applying biocontrol measures. In addition, mating type information should be considered to prevent introducing different mating type strains into chestnut stands where they are not present, as this could promote sexual reproduction and reduce the success of biocontrol of the disease.

Acknowledgements The Free University of Bozen-Bolzano is acknowledged for granting the Start-up project ChestnutBlight (TN2809) to S. Baric and the Ph.D. scholarship to F. Ahmad. Sampling activities were supported by collaborators of the Department of Forestry of the Autonomous Province of Bozen-Bolzano, members of the Chestnut Growers Association of South Tyrol and Prof. G. Tonon (Free University of BozenBolzano). The valuable support of M. Niedrist, K. Marschall and $\mathrm{M}$. Vittur at the beginning of the project is highly appreciated. M. Double (University of West Virginia) provided two isolates of $C$. parasitica used as positive controls in PCR reactions for vic loci. The authors thank the Department of Innovation, Research, University and Museums of the Autonomous Province of Bozen/Bolzano for covering the Open Access publication costs.

Funding The research project was funded by the Free University of Bozen-Bolzano. SB received the Start-up grant ChestnutBlight (TN2809), while FA was awarded a Ph.D. scholarship.

Data availability All DNA sequences obtained in the present study were deposited in GenBank. 


\section{Declarations}

Conflicts of interest/Competing interests The authors declare that they have no conflict of interest.

Consent for publication The publication has been approved by both co-authors.

Open Access This article is licensed under a Creative Commons Attribution 4.0 International License, which permits use, sharing, adaptation, distribution and reproduction in any medium or format, as long as you give appropriate credit to the original author(s) and the source, provide a link to the Creative Commons licence, and indicate if changes were made. The images or other third party material in this article are included in the article's Creative Commons licence, unless indicated otherwise in a credit line to the material. If material is not included in the article's Creative Commons licence and your intended use is not permitted by statutory regulation or exceeds the permitted use, you will need to obtain permission directly from the copyright holder. To view a copy of this licence, visit http://creativecommons.org/licenses/by/4.0/.

\section{References:}

Anagnostakis, S. L. (1977). Vegetative incompatibility in Endothia parasitica. Experimental Mycology, 1(4), 306-316.

Anagnostakis, S. L. (1987). Chestnut blight: The classical problem of an introduced pathogen. Mycologia, 79(1), 23-37.

Arabi, M. I. E., \& Jawhar, M. (2007). Molecular and pathogenic variation identified among isolates of Cochliobolus sativus. Australasian Plant Pathology, 36(1), 17-21.

ASTAT (2016). Allgemeine Landwirtschaftszählung. Statistisches Jahrbuch 2016. https://astat.provincia.bz.it/downl oads/Jahrbuch_2016.pdf. Accessed 24 September 2021.

Bandelt, H. J., Forster, P., \& Röhl, A. (1999). Median-joining networks for inferring intraspecific phylogenies. Molecular Biology and Evolution, 16(1), 37-48.

Bellini, E. (2005). The chestnut and its resources: Images and considerations. Acta Horticulturae, 693, 85-96.

Bender, O. (2002). Die Edelkastanie - Regionalentwicklung mit einer traditionellen Kulturart in den südlichen Alpen. Petermanns Geographische Mitteilungen, 146, 28-37.

Biraghi, A. (1950). La distribuzione del cancro del castagno in Italia. L'italia Forestale e Montana, 5, 18-21.

Biraghi, A. (1953). Possible active resistance to Endothia parasitica in Castanea sativa. In: Proceedings of the 11th Congress of the International Union Forest Research Organization, Rome, p. 643-645.

Bossi Fedrigotti, V., \& Fischer, C. (2015). Sustainable development options for the chestnut supply chain in South Tyrol, Italy. Agriculture and Agricultural Science Procedia, 5, 96-106.

Bryner, S. F., \& Rigling, D. (2012). Hypovirus virulence and vegetative incompatibility in populations of the chestnut blight fungus. Phytopathology, 102(12), 1161-1167.
Bryner, S. F., Prospero, S., \& Rigling, D. (2014). Dynamics of Cryphonectria hypovirus infection in chestnut blight cankers. Phytopathology, 104(9), 918-925.

Castellotti, T., \& Doria, P. (2016). La castanicoltura da frutto in Italia. Caratteristiche strutturali, risultati economici e politiche pubbliche. Rapporto di ricerca, CREA; http:// antares.crea.gov.it:8080/documents/10179/235687/Rica_ Castanicoltura03_DEF.pdf. Accessed 26 April 2021.

Cassago, A., Panepucci, R. A., Baião, A. M. T., \& HenriqueSilva, F. (2002). Cellophane based mini-prep method for DNA extraction from the filamentous fungus Trichoderma reesei. BMC Microbiology, 2(1), 14.

Coppin, E., Debuchy, R., Arnaise, S., \& Picard, M. (1997). Mating types and sexual development in filamentous ascomycetes. Microbiology and Molecular Biology Reviews, 61(4), 411-428.

Cortesi, P., Milgroom, M. G., \& Bisiach, M. (1996). Distribution and diversity of vegetative compatibility types in subpopulations of Cryphonectria parasitica in Italy. Mycological Research, 100(9), 1087-1093.

Cortesi, P., \& Milgroom, M. G. (1998). Genetics of vegetative incompatibility in Cryphonectria parasitica. Applied and Environmental Microbiology, 64(8), 2988-2994.

Cortesi, P., Rigling, D., \& Heiniger, U. (1998). Comparison of vegetative compatibility types in Italian and Swiss subpopulations of Cryphonectria parasitica. European Journal of Forest Pathology, 28(3), 167-176.

Daldal, M., Erincik, Ö., \& Wall, J. R. (2018). Geographical distribution of vegetative compatibility and mating types of Cryphonectria parasitica in İzmir, Manisa and Denizli provinces in western Turkey. Forest Pathology, 48(5), e12444.

Desprez-Loustau, M. L., Marçais, B., Nageleisen, L. M., Piou, D., \& Vannini, A. (2006). Interactive effects of drought and pathogens in forest trees. Annals of Forest Science, 63(6), 597-612.

Dutech, C., Fabreguettes, O., Capdevielle, X., \& Robin, C. (2010). Multiple introductions of divergent genetic lineages in an invasive fungal pathogen, Cryphonectria parasitica, in France. Heredity, 105(2), 220-228.

Dutech, C., Barres, B., Bridier, J., Robin, C., Milgroom, M. G., \& Ravigné, V. (2012). The chestnut blight fungus world tour: Successive introduction events from diverse origins in an invasive plant fungal pathogen. Molecular Ecology, 21(16), 3931-3946.

EU Science Hub (2019). Sweet Chestnut. The European Commission's science and knowledge service. Online article. https://ec.europa.eu/jrc/en/research-topic/forestry/qr-treeproject/sweet-chestnut. Accessed 24 September 2021.

Gao, S., \& Shain, L. (1995). Effects of water stress on chestnut blight. Canadian Journal of Forest Research, 25(6), 1030-1035.

Glass, N. L., \& Kuldau, G. A. (1992). Mating type and vegetative incompatibility in filamentous ascomycetes. Annual Review of Phytopathology, 30(1), 201-224.

Görcsös, G., Irinyi, L., Radócz, L., Tarcali, G., \& Sándor, E. (2015). Diversity of Cryphonectria parasitica populations from the Carpathian Basin. Acta Microbiologica et Immunologica Hungarica, 62(3), 247-266. 
Gottlieb, A. M., \& Lichtwardt, R. W. (2001). Molecular variation within and among species of Harpellales. Mycologia, 93(1), 66-81.

Heiniger, U., \& Rigling, D. (1994). Biological control of chestnut blight in Europe. Annual Review of Phytopathology, 32(1), 581-599.

Kasuga, T., White, T. J., \& Taylor, J. W. (2002). Estimation of nucleotide substitution rates in Eurotiomycete fungi. Molecular Biology and Evolution, 19(12), 2318-2324.

Krstin, L., Novak-Agbaba, S., Rigling, D., Krajačić, M., \& Ćurković Perica, M. (2008). Chestnut blight fungus in Croatia: Diversity of vegetative compatibility types, mating types and genetic variability of associated Cryphonectria hypovirus 1. Plant Pathology, 57(6), 1086-1096.

Kronstad, J. W., \& Staben, C. (1997). Mating type in filamentous fungi. Annual Review of Genetics, 31(1), 245-276.

Leigh, J. W., \& Bryant, D. (2015). PopART: Full-feature software for haplotype network construction. Methods in Ecology and Evolution, 6(9), 1110-1116.

Lévesque, C. A., \& De Cock, A. W. (2004). Molecular phylogeny and taxonomy of the genus Pythium. Mycological Research, 108(12), 1363-1383.

Liu, Y. C., Cortesi, P., Double, M. L., MacDonald, W. L., \& Milgroom, M. G. (1996). Diversity and multilocus genetic structure in populations of Cryphonectria parasitica. Phytopathology, 86(12), 1344-1351.

Mair, K. (2009). Die Esskastanien-Gallwespe - ein neuer, gefährlicher Schädling. Obstbau Weinbau, 4/2009, 149150. https://www.obstbauweinbau.info/obstbauweinbau/ pdf/stepone/data/pdf/84/09/00/mair_esskastanien_gallw espe.pdf. Accessed 24 September 2021.

Maresi, G., Minerbi, S., Sottovia, A., \& Turchetti, T. (1993). Der Kastanienrindenkrebs in Südtirol. Allgemeine Forstzeitschrift für Waldwirtschaft und Umweltvorsorge, 48(3), 140-144.

Mangil, E., \& Erincik, Ö. (2018). Sexual reproduction contributes to vegetative compatibility type diversity in the population of Cryphonectria parasitica in the East Black Sea region of Turkey. Australasian Plant Pathology, 47(3), 301-310.

Marra, R. E., \& Milgroom, M. G. (1999). PCR amplification of the mating-type idiomorphs in Cryphonectria parasitica. Molecular Ecology, 8(11), 1947-1950.

McGuire, I. C., Marra, R. E., Turgeon, B. G., \& Milgroom, M. G. (2001). Analysis of mating-type genes in the chestnut blight fungus, Cryphonectria parasitica. Fungal Genetics and Biology, 34(2), 131-144.

Meyer, J. B., Gallien, L., \& Prospero, S. (2015). Interaction between two invasive organisms on the European chestnut: Does the chestnut blight fungus benefit from the presence of the gall wasp? FEMS Microbiology Ecology, 91(11), 122.

Milgroom, M. G., Wang, K., Zhou, Y., Lipari, S. E., \& Kaneko, S. (1996). Intercontinental population structure of the chestnut blight fungus, Cryphonectria parasitica. Mycologia, 88(2), 179-190.

Milgroom, M. G., \& Cortesi, P. (2004). Biological control of chestnut blight with hypovirulence: A critical analysis. Annual Review of Phytopathology, 42, 311-338.

Milgroom, M. G., Sotirovski, K., Spica, D., Davis, J. E., Brewer, M. T., Milev, M., \& Cortesi, P. (2008). Clonal population structure of the chestnut blight fungus in expanding ranges in southeastern Europe. Molecular Ecology, 17(20), 4446-4458.

Mlinarec, J., Ježić, M., Ćosić, J., \& Ćurković-Perica, M. (2018). Multilocus PCR assay reveals high diversity of vegetative compatibility types in populations of Cryphonectria parasitica in Croatia. Plant Pathology, 67(3), 741-749.

Montenegro, D., Aguin, O., Sainz, M. J., Hermida, M., \& Mansilla, J. P. (2008). Diversity of vegetative compatibility types, distribution of mating types and occurrence of hypovirulence of Cryphonectria parasitica in chestnut stands in NW Spain. Forest Ecology and Management, 256(5), 973-980.

Morozov, A. Y., Robin, C., \& Franc, A. (2007). A simple model for the dynamics of a host-parasite-hyperparasite interaction. Journal of Theoretical Biology, 249(2), 246-253.

Myteberi, I. F., Lushaj, A. B., Keča, N., Lushaj, A. B., \& Lushaj, B. M. (2013). Diversity of Cryphonectria parasitica, hypovirulence, and possibilities for biocontrol of chestnut canker in Albania. International Journal of Microbiology Research and Reviews, 1, 11-21.

Nagy, L. G., Kocsubé, S., Csanádi, Z., Kovács, G. M., Petkovits, T., Vágvölgyi, C., \& Papp, T. (2012). Re-mind the gap! Insertion-deletion data reveal neglected phylogenetic potential of the nuclear ribosomal internal transcribed spacer (ITS) of fungi. PloS one, 7(11), e49794.

Nei, M. (1973). Analysis of gene diversity in subdivided populations. Proceedings of the National Academy of Sciences, 70(12), 3321-3323.

Pennisi, A. M., Sammarco, G., Spica, D., Cacciola, S. O. (2005). Characterization of Cryphonectria parasitica populations in southern Italy. Acta Horticulturae, 693, 535-542.

Pérez-Sierra, A., Romón-Ochoa, P., Gorton, C., Lewis, A., Rees, H., Van Der Linde, S., \& Webber, J. (2019). High vegetative compatibility diversity of Cryphonectria parasitica infecting sweet chestnut (Castanea sativa) in Britain indicates multiple pathogen introductions. Plant Pathology, 68(4), 727-737.

Peters, F. S., Holweg, C. L., Rigling, D., \& Metzler, B. (2012). Chestnut blight in south-western Germany: Multiple introductions of Cryphonectria parasitica and slow hypovirus spread. Forest Pathology, 42(5), 397-404.

Peters, F. S., Bußkamp, J., Prospero, S., Rigling, D., \& Metzler, B. (2014). Genetic diversification of the chestnut blight fungus Cryphonectria parasitica and its associated hypovirus in Germany. Fungal Biology, 118(2), 193-210.

Pielou, E. C. (1966). The measurement of diversity in different types of biological collections. Journal of Theoretical Biology, 13, 131-144.

Poczai, P., \& Hyvönen, J. (2010). Nuclear ribosomal spacer regions in plant phylogenetics: Problems and prospects. Molecular Biology Reports, 37(4), 1897-1912.

Prospero, S., \& Rigling, D. (2012). Invasion genetics of the chestnut blight fungus Cryphonectria parasitica in Switzerland. Phytopathology, 102(1), 73-82.

Rigling, D., \& Prospero, S. (2018). Cryphonectria parasit$i c a$, the causal agent of chestnut blight: Invasion history, 
population biology and disease control. Molecular Plant Pathology, 19(1), 7-20.

Robin, C., \& Heiniger, U. (2001). Chestnut blight in Europe: Diversity of Cryphonectria parasitica, hypovirulence and biocontrol. Forest, Snow and Landscape Research, 76(3), 361-367.

Robin, C., Capdevielle, X., Martin, M., Traver, C., \& Colinas, C. (2009). Cryphonectria parasitica vegetative compatibility type analysis of populations in south-western France and northern Spain. Plant Pathology, 58(3), 527-535.

Robin, C., Lanz, S., Soutrenon, A., \& Rigling, D. (2010). Dominance of natural over released biological control agents of the chestnut blight fungus Cryphonectria parasitica in south-eastern France is associated with fitness-related traits. Biological Control, 53(1), 55-61.

Short, D. P., Double, M., Nuss, D. L., Stauder, C. M., MacDonald, W., \& Kasson, M. T. (2015). Multilocus PCR assays elucidate vegetative incompatibility gene profiles of Cryphonectria parasitica in the United States. Applied and Environmental Microbiology, 81(17), 5736-5742.

Sotirovski, K., Papazova-Anakieva, I., Grünwald, N. J., \& Milgroom, M. G. (2004). Low diversity of vegetative compatibility types and mating type of Cryphonectria parasitica in the southern Balkans. Plant Pathology, 53(3), 325-333.

Takamatsu, S., Hirata, T., Sato, Y., \& Nomura, Y. (1999). Phylogenetic relationships of Microsphaera and Erysiphe section Erysiphe (powdery mildews) inferred from the rDNA ITS sequences. Mycoscience, 40(3), 259-268.
Tramer, E. J. (1969). Bird species diversity: Components of Shannon's formula. Ecology, 50(5), 927-929.

Trestic, T., Uscuplic, M., Colinas, C., Rolland, G., Giraud, A., \& Robin, C. (2001). Vegetative compatibility type diversity of Cryphonectria parasitica populations in BosniaHerzegovina, Spain and France. Forest, Snow and Landscape Research, 76(3), 391-396.

Tuomisto, H. (2010). A consistent terminology for quantifying species diversity? Yes, it does exist. Oecologia, 164(4), 853-860.

Waldboth, M., \& Oberhuber, W. (2009). Synergistic effect of drought and chestnut blight (Cryphonectria parasitica) on growth decline of European chestnut (Castanea sativa). Forest Pathology, 39(1), 43-55.

Windegger, A. (1994). La lotta biologica contro il cancro del castagno in Alto Adige. Bachelor's Thesis at the University of Firenze, Firenze, Italy.

Yeh, F.C., Yang, R.C., Boyle, T., Ye, Z.H. \& Mao, J.X. (1999). POPGENE, version 1.32: the user friendly software for population genetic analysis. Molecular Biology and Biotechnology Centre, University of Alberta, Edmonton, AB, Canada.

Zamora, P., Martín, A. B., Rigling, D., \& Diez, J. J. (2012). Diversity of Cryphonectria parasitica in western Spain and identification of hypovirus-infected isolates. Forest Pathology, 42(5), 412-419. 